\title{
Convergence or divergence: where do short-tailed shearwaters forage in the Southern Ocean?
}

\author{
Eric J. Woehler ${ }^{1,2, *}$, Ben Raymond ${ }^{2}$, David J. Watts ${ }^{2}$ \\ ${ }^{1}$ Institute of Antarctic and Southern Ocean Studies, University of Tasmania, Private Bag 77, Hobart 7001, Tasmania, Australia \\ ${ }^{2}$ Australian Antarctic Division, Department of the Environment and Heritage, Channel Highway, Kingston 7050, \\ Tasmania, Australia
}

\begin{abstract}
Short-tailed shearwaters Puffinus tenuirostris (STSH) make use of a number of physical oceanographic features on their foraging trips to the Southern Ocean from their breeding colonies in southeast Australia. We examined the patterns in STSH at sea in the southern Indian Ocean with respect to various physical oceanographic features. Between mid-September and mid-January, there was a prominent peak in STSH densities associated with the Antarctic Polar Front (APF). A secondary peak in foraging STSH densities associated with the Antarctic Divergence (AD) was also present from late November to mid April. The high densities of STSH associated with the APF and AD support the interpretation that these features are concentrating prey in a predictable manner. As the summer breeding season progresses, STSH are observed farther southward and westward, reaching their greatest distances from their colonies at the time when they are feeding chicks. The ice edge did not appear to be a foraging focus for STSH, but represented the southern-most limit of STSH foraging in the Southern Ocean. Throughout this southward and westward movement, STSH avoid areas with pack ice. As the Marginal Ice Zone (MIZ) retreats southward, the STSH follow and, by mid summer, are foraging over the Antarctic continental shelf. The shelf break, MIZ and AD overlap spatially during the summer months as the MIZ retreats southward past the AD and over the continental shelf. The individual influences of each of these 3 oceanographic features could not be disentangled. The southward shift by STSH from the APF to the more productive MIZ/AD/continental shelf is associated with the hatching of eggs and the onset of the elevated energy demands of growing chicks.
\end{abstract}

KEY WORDS: Short-tailed shearwater • Puffinus tenuirostris • Foraging • Southern Ocean • Oceanographic features · Prey predictability

\section{INTRODUCTION}

The breeding seabird community of the Antarctic comprises approximately 20 species, with another 60 or so non-breeding species recorded in the region. Satellite transmitters and at-sea surveys have provided direct evidence that many of these non-breeding species forage within the Southern Ocean surrounding the Antarctic. Numerous species of temperate and mid-latitude albatrosses Diomedea spp. and Thalassarche spp. and giant petrels Macronectes spp. have been tracked south of $60^{\circ} \mathrm{S}$ in the Indian, Pacific and Atlantic sectors of the Southern Ocean for extended periods
(BirdLife International 2004), complementing observations from at-sea surveys at local to synoptic scales.

The non-breeding seabird community is more diverse than the breeding community in the Ross Sea (Ainley et al. 1984), South Atlantic Ocean and Weddell Sea region (Ainley et al. 1993, 1994) and in the Indian Ocean sector of the Southern Ocean (Woehler 1997 , Woehler et al. 1991, 2003). In addition to the albatrosses and larger petrels, a diverse guild of smaller petrels is regularly observed at high latitudes in the Southern Ocean (e.g. Ainley et al. 1984, Abrams 1985, Veit \& Hunt 1991, Woehler et al. 1991). Among these are short-tailed shearwaters Puffinus tenuirostris 
(hereafter STSH), a medium-sized migratory petrel (mass 500 to 800 g, $1 \mathrm{~m}$ wingspan) that breeds in small to vast colonies on southeast mainland Australia and migrates annually to the North Pacific Ocean and Bering Sea (Hunt et al. 1996, Weimerskirch \& Cherel 1998, Baduini et al. 2001). The current population estimate is of approximately 9 million breeding pairs, with another 5 or so million non-breeding individuals, with recent suggestions that the species' population may be increasing (Skira et al. 1996). The largest colonies are on islands in Bass Strait $\left(40^{\circ} \mathrm{S}\right)$, which separates Tasmania from mainland Australia.

STSH are now known to be major consumers of Antarctic marine resources (Woehler 1995, 1997, Weimerskirch \& Cherel 1998). Early sightings in the 1940s (Routh 1949) were subsequently confirmed with ship-strikes (Kerry et al. 1983) and extensive at-sea sightings (Veit \& Hunt 1991, Woehler et al. 1991, 2003, Woehler 1997). Satellite tracking data from 1 nonbreeding (Nicholls et al. 1998) and of 3 breeding individuals (Klomp \& Schultz 2000) has provided preliminary, but limited, data on flight paths and potential foraging locations. However, these 2 studies were unable to provide data on population foraging strategies, or of the relationship between physical oceanographic features and foraging efforts.

Physical oceanographic processes that concentrate marine organisms at or close to the sea surface (and thus available to foraging seabirds) facilitate energy flow to the seabird community. Within the Southern Ocean Ecosystem (SOE), both sea ice (Ainley \& Jacobs 1981, Ainley et al. 1984, 1986, 1992, van Franeker 1992) and continental shelf topography (Ainley \& Jacobs 1981, Ainley et al. 1984, Ainley \& DeMaster 1990) have been shown to concentrate prey organisms at densities sufficiently high for foraging seabirds to use effectively. Ainley \& DeMaster (1990) suggested that little evidence exists to indicate that convergences in the Southern Ocean concentrate food for seabirds (but see Griffiths et al. 1982 and Ainley et al. 1984).

Each spring and summer, the sea ice surrounding the Antarctic continent melts and recedes and forms the marginal ice zone (MIZ), an area of open water with varying concentrations of sea ice (Knox 1994). The MIZ is present each year from November to March, moving southward towards the Antarctic continent as the summer progresses. Previous studies have shown that the Antarctic MIZ is characterised by enhanced biological activity at all trophic levels, owing to the increasing stratification of the surface waters from the melting ice that alters surface salinity gradients, and the exposure of nutrient rich waters to sunlight (Smith \& Sakshaug 1990, Knox 1994 and references therein). Under these conditions, rapid but patchy increases in phytoplankton biomass occur.
Within the MIZ, primary productivity (Wilson et al. 1986, Mathot et al. 1992, Veth et al. 1992), secondary productivity (Smith \& Schnack-Schiel 1990) and top order predators (seabirds, seals and whales: Ainley \& Jacobs 1981, Ainley \& DeMaster 1990, Hunt 1991, van Franeker 1992), have been recorded at levels significantly higher than surrounding, non-ice influenced waters. Smith et al. (1988) estimated that the primary productivity at the ice-edge contributes significantly to the annual production budget of Antarctic surface waters. Close to the Antarctic continent, the Antarctic Divergence (AD, alternatively referred to as the southern boundary of the Antarctic Circumpolar Current) is an oceanographic boundary between 2 water masses flowing parallel to the Antarctic coast, but in opposing directions. The role of the $\mathrm{AD}$ in enhancing biological production by processes such as upwelling is presently unknown, but could be expected to be substantial (Ainley \& DeMaster 1990).

We analysed data collected over 23 years of at-sea surveys between Australia and East Antarctica, and examined fine scale temporal and broad scale spatial patterns in the distribution and abundance of STSH in the Indian sector of the Southern Ocean adjacent to Antarctica. The aim of the present study was to examine the relationship between foraging STSH and physical oceanographic features that provide spatially and/or temporally predictable cues to the location of their marine prey in the Southern Ocean.

\section{METHODS}

Details of methodologies used to collect seabird-atsea data and concomitant physical oceanographic and environmental data are described elsewhere (Woehler 1995, 1997). Briefly, Prydz Bay is in the southwest Indian Ocean between $60^{\circ} \mathrm{E}$ and $90^{\circ} \mathrm{E}$, and south of $60^{\circ} \mathrm{S}$ to the Antarctic continent. Observations of the numbers and behaviours of all species of seabirds present within a $300 \mathrm{~m}$ forward-quadrant of the ship were recorded. Ship-followers were excluded from all analyses. Observations of STSH at sea between Australia and the Antarctic were combined for $23 \mathrm{yr}$ between 1980/81 and 2003/04 and then examined based on 6 periods corresponding to their breeding phenology (Table 1). These periods and dates were selected based on the high degree of synchronicity of breeding season events, both within and among seasons (Marchant \& Higgins 1990). The synchronicity of breeding season events allowed at-sea observations to be pooled across years. The data were drawn from 34166 at-sea surveys and comprised 5896 STSH sightings, totalling approximately 170000 ind. Sightings of STSH within each of the 6 breeding periods were 
Table 1. Puffinus tenuirostris. Times of STSH breeding season events in southeastern Australia

\begin{tabular}{|ll|}
\hline Period & Breeding season event(s), date range \\
\hline 1 & Pre-return to colonies (1-20 Sep) \\
2 & Return to colonies, reoccupation of nests (21 \\
& Sep-5 Nov) \\
3 & Pre-egg exodus (6-25 Nov) \\
4 & Return to nests, incubation (26 Nov-20 Jan) \\
5 & Egg hatch, rearing chicks (21 Jan-15 Apr) \\
6 & Adult departure from nests (16 Apr-31 Aug)
\end{tabular}

binned into cells of $1^{\circ}$ latitude $\times 1^{\circ}$ longitude. Binned count data were log (count +1$)$ transformed. We generated figures showing the spatial distribution of surveys and STSH sightings during each of the 6 periods, and calculated the positions of STSH sightings with respect to a number of physical oceanographic features. The statistical significance of the frequency distribution of observations with respect to these features was assessed by randomly reassigning the positions (latitude and longitude) of STSH sightings within a given time period, and the number of sightings at a given distance from a feature were compared to the original observations without randomisation. The procedure was repeated 1000 times and observation densities that were higher than expected under randomisation were identified (a significance level of $5 \%$ was used).

Physical environmental data collected contemporaneously with seabird observations comprised sea surface temperature $\left({ }^{\circ} \mathrm{C}\right)$, sea state (Beaufort), cloud cover (oktas), precipitation (precipitation types), wind force (Beaufort scale) and air pressure (hPa). Sea ice concentration data were taken from passive microwave satellite images (Comiso 2003). The northern extent of the ice pack was calculated as the latitude at which the sea ice cover decreased below $15 \%$. The position of the ice pack edge was calculated on a daily basis for comparison with STSH sightings. For the 92 sightings that were obtained more recently than the temporal coverage of the sea ice data (i.e. those made after 31 December 2003), the average on that day over all years was used. The $1000 \mathrm{~m}$ isobath (GEBCO Digital Atlas, British Oceanographic Data Centre 1994) was used to delineate the outer extent of the Antarctic continental shelf. The shelf break is usually considered to be at a depth of approximately $600 \mathrm{~m}$; however, there were insufficient data for the $600 \mathrm{~m}$ isobath within the study area. The locations of the Antarctic Polar Front (APF) and the AD were taken from Orsi et al. (1995). Estimates of surface chlorophyll a ( $\mathrm{chl}$ a) concentrations were obtained from SeaWiFS data (http://seawifs.gsfc. nasa.gov/SEAWIFS.html).

\section{RESULTS}

\section{Spatial patterns in relation to breeding season phenology}

There was a general southward and westward progression of STSH sightings from the Southern Ocean surrounding Tasmania towards the Antarctic from the start of the reoccupation period (21 September) until the end of the chick-rearing period in mid April (Fig. 1). The farthest observations were made late in the breeding season, more than $5000 \mathrm{~km}$ from the colonies in southeast Australia, when adults are feeding chicks.

During the 79910 min surveys, there were 2 sightings (comprising $3 \mathrm{STSH}$ ) southeast of Tasmania before their return to colonies (between 1 and 20 September). The sightings were approximately $500 \mathrm{~km}$ off the southeast coast. At this time, the birds would have been returning from their migration to the North Pacific Ocean (Baduini et al. 2001) and would not yet have reoccupied their burrows.

The reoccupation period (21 September to 5 November) is the period following the birds' return to southeast Australia, during which time the birds (re-)excavate and reoccupy their burrows and (re-)establish their pair bonds. During this period, there were 606 sightings to the south and west of Tasmania, extending past the $\mathrm{APF}$ at approximately $55^{\circ} \mathrm{S}, 130^{\circ} \mathrm{E}$ (Fig. 1a), during a total of 4823 surveys. The southern-most sightings were at $60^{\circ} \mathrm{S}, 123^{\circ} \mathrm{E}$, approximately halfway between the APF and the pack ice edge. The majority of birds sighted (99\%) were north of or at the APF, with approximately 400 birds sighted south of the APF. The highest numbers of STSH (up to 750 per survey) were observed around $53^{\circ} \mathrm{S}, 138^{\circ} \mathrm{E}$. During this period, the ice edge was approximately 6 to $7^{\circ}$ latitude south of the $\mathrm{APF}$, and 1 to $2^{\circ}$ north of the AD.

During the pre-egg exodus (6 to 25 November), STSH are at sea feeding in order to obtain energy for the production of the egg (females) or for undertaking the first incubation shift of between 10 and $18 \mathrm{~d}$ (males). During a total of 2007 surveys, the highest densities of STSH (up to 300 birds per survey) were seen near or at the APF at $115^{\circ} \mathrm{E}$ and $132^{\circ} \mathrm{E}$, approximately $2000 \mathrm{~km}$ southwest of Tasmania (Fig. 1b). Approximately $93 \%$ of STSH sighted were between Tasmania and the APF. There was a westward movement of STSH, with the farthest west sighting at $60^{\circ} \mathrm{S}, 102^{\circ} \mathrm{E}$. An unexpected result was that the fewest STSH were sighted per survey (2.4) during the pre-egg exodus, compared with any other period excepting pre-arrival and nest departure (return to colony: 7.0 STSH/survey; incubation: 6.3, chickrearing: 4.9 ). 
(a) Return to nests, 21 Sep-5 Nov

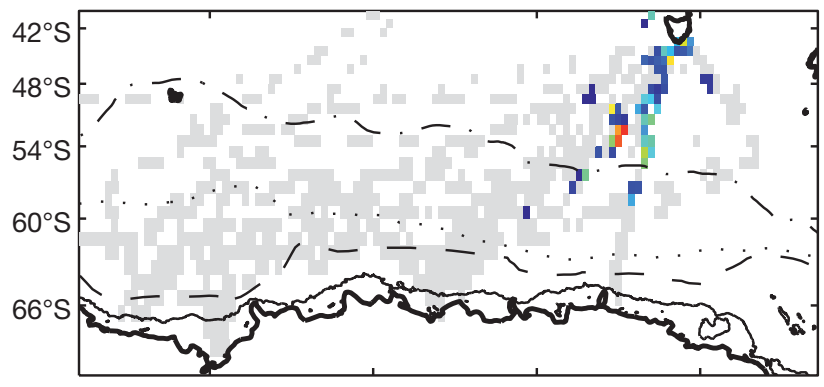

(c) Incubation, 26 Nov-20 Jan (b) Pre-egg exodus, 6-25 Nov

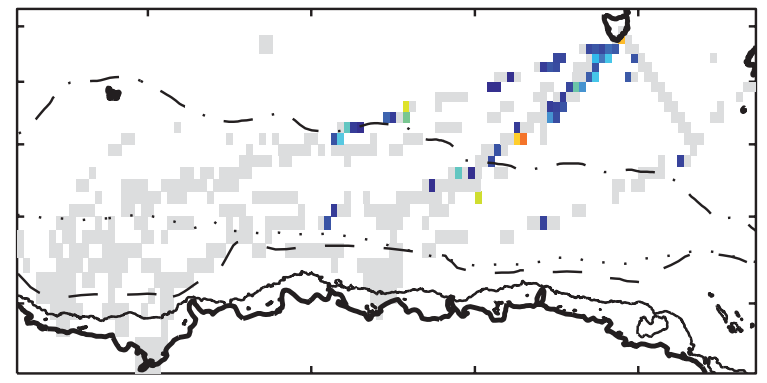

(d) Brooding, 21 Jan-15 Apr

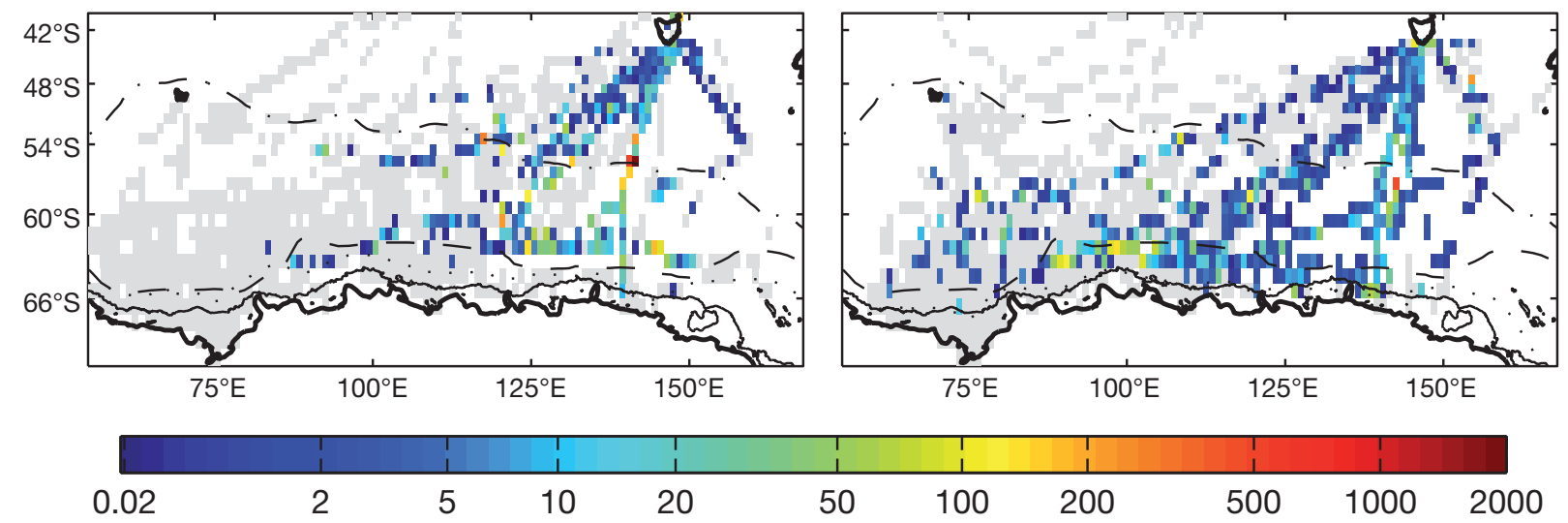

Fig. 1. Puffinus tenuirostris. At-sea sightings of STSH in the Indian Ocean sector of the Southern Ocean, 1980/81 to 2003/04 (units: no. of STSH per 10 min survey, binned at $1^{\circ}$ lat $\times 1^{\circ}$ long, see 'Methods'). Plots show distributions during 4 periods related to breeding season events: (a) adults return to colonies in southeastern Australia (21 Sep-5 Nov); (b) during pre-egg exodus (6-25 Nov); (c) during subsequent return to nests, egg laying and incubation (26 Nov-20 Jan); (d) egg hatch and rearing chicks (21 Jan-15 Apr). Colour scale: no. of STSH sighted per survey. For clarity, light grey was used to indicate survey effort but no sightings. Dot-dashed and dashed lines: Antarctic Polar Front (APF) and Antarctic Divergence (AD), respectively (Orsi et al. 1995), dotted line: mean northern-most extent of sea ice at the mid-point of each period, thin solid line: seaward extent of Antarctic continental shelf (1000 m isobath)

During the incubation period (26 November to 20 January), at least 1 bird is present in a burrow at any time, and an egg is never left unattended in a burrow. When away from their colonies, STSH are foraging to replenish energy reserves lost during incubation shifts and to prepare for the subsequent incubation shifts. The highest densities of STSH (2000 birds per survey) were reported from the $\mathrm{APF}$ at $142^{\circ} \mathrm{E}$, with generally high numbers in the area between $115^{\circ} \mathrm{E}$ and $145^{\circ} \mathrm{E}$ and from the APF south to $62^{\circ} \mathrm{S}$ (Fig. 1c). The westernmost record was from the central Prydz Bay region on the East Antarctic coast at $62^{\circ} \mathrm{S}, 83^{\circ} \mathrm{E}$, approximately $4700 \mathrm{~km}$ from Tasmania. Approximately 36000 of 65000 STSH sighted (55\%) were between Tasmania and the APF in this period. These sightings were made during 3186 of 10286 surveys (31\%). The vast majority of birds $(97 \%)$ were sighted east of $110^{\circ} \mathrm{E}$, whereas just 4494 of 10286 surveys (44\%) were made in the same area. More than $96 \%$ of STSH were north of the $\mathrm{AD}$ (Table 2).
The chick-rearing period (21 January to 15 April) saw the greatest westward extent of STSH sightings, with observations in the western areas of Prydz Bay $\left(67^{\circ} \mathrm{S}, 61^{\circ} \mathrm{E}\right)$, approximately $6000 \mathrm{~km}$ from Tasmania (Fig. 1d). High densities of STSH were observed at the $\mathrm{APF}$ near $56^{\circ} \mathrm{S}, 142^{\circ} \mathrm{E}$ (up to 480 birds per survey) and in the MIZ at $62^{\circ} \mathrm{S}, 100^{\circ} \mathrm{E}$ (150 birds per survey). STSH were observed over much of the Southern Ocean surveyed in this study. During chick-rearing, $32 \%$ of birds sighted were between Tasmania and the APF during 3467 of 13527 surveys (26\%). Approximately $66 \%$ of birds were sighted east of $110^{\circ} \mathrm{E}$ during 5288 of 13527 surveys (39\%), $65 \%$ of STSH were north of the AD and an additional $29 \%$ were between the AD and the shelf break (Table 2).

STSH were still present in eastern Prydz Bay during the adult departure period (16 April to 31 August); however, few STSH were observed (approximately 450 ind. in total). The majority of the birds (90\%) were sighted north of APF; these were observed in 1124 of 
Table 2. Puffinus tenuirostris. Percentages of STSH observed with respect to 4 oceanographic features in the Southern Ocean, based on 34166 surveys of approximately 170000 STSH from 1980/81 to 2003/04 for 6 periods of the breeding season (Table 1). Numbers in brackets: percentages of surveys with respect to named feature, 'within $5^{\circ}$ : within $5^{\circ}$ latitude $\left( \pm 5^{\circ}\right.$ on either side) of named feature, APF: Antarctic Polar Front, AD: Antarctic Divergence

\begin{tabular}{|lcccccc|}
\hline Feature & Pre-return (1) & Return (2) & Exodus (3) & Incubation (4) & Chick-rearing (5) & Departure (6) \\
\hline APF (at or north of) & $100(44.3)$ & $98.8(41.0)$ & $93.3(36.0)$ & $55.3(31.0)$ & $31.8(25.6)$ & $89.9(41.3)$ \\
APF (within 5 ${ }^{\circ}$ a & $0.0(5.3)$ & $18.6(16.9)$ & $76.3(12.5)$ & $48.9(9.2)$ & $14.9(8.8)$ & $62.8(28.5)$ \\
Ice-edge (at or north of) & $100(98.5)$ & $100(69.4)$ & $100(70.9)$ & $99.5(80.7)$ & $95.3(87.1)$ & $99.7(79.3)$ \\
AD (at or north of) & $100(100)$ & $100(88.0)$ & $100(86.2)$ & $96.4(70.8)$ & $65.1(62.3)$ & $96.8(80.7)$ \\
AD (within 5 $5^{\circ}$ & $0.0(3.0)$ & $0.0(24.2)$ & $0.1(24.5)$ & $21.8(34.3)$ & $43.7(36.5)$ & $9.0(21.8)$ \\
Antartic shelf break (at or north of) & $100(100)$ & $100(97.2)$ & $100(94.3)$ & $99.0(90.0)$ & $93.9(83.8)$ & $100(94.0)$ \\
\hline
\end{tabular}

$2724(41 \%)$ of surveys. Almost all birds sighted (99\%) were east of $110^{\circ} \mathrm{E}$; these sightings were made in 1947 of 2724 surveys $(71 \%)$.

\section{Spatial patterns in relation to physical oceanographic features}

We examined the spatial and temporal patterns in STSH distributions at sea in relation to 4 physical features: the ice edge, the APF, the AD and the distance from the Antarctic continental shelf break (Table 2, Fig. 2).

Ice edge

Approximately $2 \%$ of all STSH observed in the period 1980/81 to 2003/04 (approximately 3500 STSH) were reported south of the ice edge, despite the fact that approximately $19 \%$ of surveys were made south of the ice edge (6364 of 34 166). All STSH observations south of the ice edge were during the incubation, chick-rearing and adult departure phases (26 November onwards) when STSH were at their greatest southward and westward extents from their colonies. The ice edge did not appear to be a foraging focus for the STSH, as there are no peaks in STSH densities at the ice edge (Fig. 2). However, it is clear that the ice edge represents the southern-most limit of STSH foraging extent in the Southern Ocean. This is likely to be due to the difficulties of feeding in areas where sea ice is present (see also Ainley et al. 1984, Veit $\&$ Hunt 1991); STSH can dive to $30 \mathrm{~m}$ or more and the presence of ice may interfere with their pre- or post-dive behaviour on the surface (Weimerskirch \& Cherel 1998).

\section{Antarctic Polar Front (APF)}

STSH were observed southward of the APF for all periods of their breeding season except for the pre- return phase. Birds were generally not observed more than $5^{\circ}$ of latitude south of the APF until the end of the pre-egg exodus (26 November onwards). High densities of STSH were observed within $5^{\circ}$ of the APF between 21 September and 15 April (Fig. 2). In this study, STSH densities peaked around the APF for the majority of their breeding season, but were particularly evident for the period 21 September to 20 January (Fig. 2).

\section{Antarctic Divergence (AD)}

STSH were observed south of the AD only during the incubation, chick-rearing and adult departure phases (26 November onwards; Table 2, Fig. 2). Just over $15 \%$ of STSH sighted were south of the AD, observed in $28 \%$ of surveys. During the reoccupation and pre-egg exodus phases (21 September to 25 November), high densities of STSH were observed at $10^{\circ}$ and $20^{\circ}$ north of the $\mathrm{AD}$; these concentrations were at the $\mathrm{APF}$ and just south of Tasmania, respectively (Fig. 1). A broader distribution was observed for the incubation and chick-rearing periods (26 November to 15 April) (Fig. 2). There was a peak in STSH densities at the AD during the incubation phase, and just south of the AD during the chick-rearing phase. The latter peak was closer to the position of the ice edge than the $\mathrm{AD}$ (Fig. 2).

\section{Antarctic continental shelf}

Approximately $3 \%$ of all STSH observed (approximately 4600 birds) were reported over the Antarctic continental shelf, compared to $11 \%$ of the survey effort. As with the ice edge, all STSH were observed during the incubation, chick-rearing and adult departure phases (26 November onwards) when STSH were at their greatest southward and westward extents from their colonies, Fig. 2. 

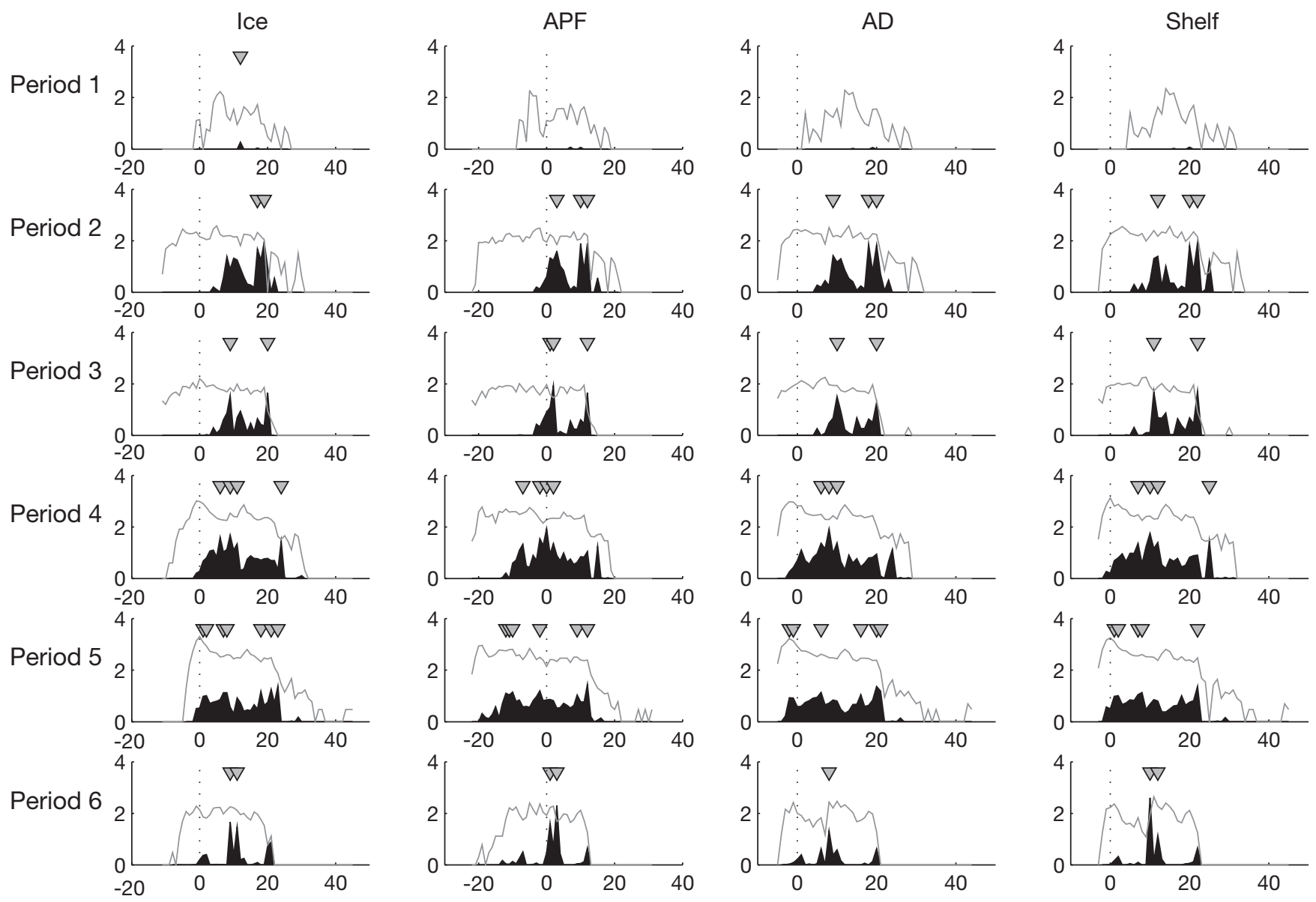

' latitude south (negative) and north (positive) of feature

Fig. 2. Puffinus tenuirostris. Survey effort (log [no. of surveys +1$])$ and observed densities (log [no. of STSH per 10 min survey +1$]$ ) of STSH in the Indian Ocean sector of the Southern Ocean, 1980/81 to 2003/04, with respect to 4 physical oceanographic features (both surveys and densities log-transformed). Triangles indicate STSH densities higher than expected by chance (assessed by randomisation; see text). Note: log-transformed number of STSH per survey multiplied by 5 in Periods 1 and 6 due to low numbers of birds sighted. Abscissae: latitudinal distance north and south of each feature in degrees latitude, thin grey line: no. of surveys, black-shaded region: no. of STSH observed per survey. Plots correspond to 6 periods related to breeding season events (see

Table 1 for periods and Table 2 for heading definitions)

\section{DISCUSSION}

\section{Limitations of the data}

Observations of STSH at sea are unable to determine the breeding status of the individuals reported. In contrast to breeding adults, pre-breeders, non-breeding or failed breeders would not be constrained to return to their colonies to feed chicks, and would be able to use different foraging strategies to those of breeding birds (e.g. to undertake extended foraging trips). However, the inclusion of non-breeding birds should have little effect on our findings. With a breeding population of approximately 9 million pairs from a global population of 23 million birds (Skira et al. 1996, I. Skira pers. comm.), the vast majority of birds observed in the
Southern Ocean are breeding birds foraging for themselves and their chick. Confusion with sooty shearwaters Puffinus griseus is also unlikely to be a concern for this study, as there are very few sightings of sooty shearwaters west of Macquarie Island $\left(54^{\circ} \mathrm{S}, 159^{\circ} \mathrm{E}\right)$ in the Indian Ocean (Woehler 1997, Woehler et al. 2003, E. Woehler unpubl. data).

The distributions of STSH sightings at sea in the Southern Ocean were compared to the positions of physical oceanographic features that are not absolute in their locations. The positions of the 2 fronts (APF and AD) vary with time. The APF (as defined by satellitederived sea surface temperatures) has been shown to change position by up to 5 degrees in latitude both intra- and inter-seasonally in the region $90^{\circ} \mathrm{E}$ to $150^{\circ} \mathrm{E}$ (Moore et al. 1999). We used a fixed APF position cal- 
culated from historical data up to 1990 (Orsi et al. 1995), because fine scale data on the exact location were not available for the duration of the study period. The variation in the foraging range of the birds (up to $25^{\circ}$ latitude) is 5 -fold that of the latitudinal variation in the position of the $\mathrm{APF}_{\text {, }}$ and thus is unlikely to confound our results.

\section{Spatio-temporal patterns in foraging STSH in the Southern Ocean - predictability in their prey?}

Spatial and temporal predictability of prey is important to foraging seabirds, especially for long-distance foragers such as shearwaters that rely on physical oceanographic features to concentrate their prey at densities that are energetically efficient to exploit. Shearwaters may also rely on swarming behaviour of their prey species (in particular by crustaceans, but see Weimerskirch \& Cherel 1998 for a full inventory of prey taxa) to create patches at sufficient densities to be exploited profitably (Hunt et al. 1996, Lovvorn et al. 2001, Jahncke et al. 2005).

This study has clearly shown the attraction of the APF and the barrier that the MIZ presents to foraging STSH during their summer breeding season. For approximately $4 \mathrm{mo}$, from mid September to mid January, there is a peak in STSH densities associated with the APF; in addition, there is a peak in foraging $\mathrm{STSH}$ densities at the AD from late November to mid-April (Fig. 2). The high densities of foraging STSH associated with the APF support the interpretation that the APF is acting to concentrate prey for STSH in a temporally and spatially predictable manner. As the summer breeding season progresses, foraging STSH are observed farther southward and westward, reaching their greatest distances from their colonies at the time when they are feeding their chicks. Throughout this southward and westward movement, the STSH are constrained by the presence of pack ice-the $15 \%$ cover that represents the southern extent of the MIZ limits the southward extent of foraging birds. As the MIZ retreats southward, the foraging STSH follow, and by mid summer, are foraging over the Antarctic continental shelf.

There are few published data available that document elevated seabird abundances at the APF. Griffiths et al. (1982) reported maxima in species diversity and biomass associated with the APF in the Southern Ocean south of South Africa. Ainley et al. (1984) reported high densities of the closely-related sooty shearwaters throughout the APF region in the Ross Sea. However, Ainley \& DeMaster (1990) suggested that there was little evidence of enhanced biological activity (including seabirds) at the APF, and suggested that the perception of enhancement may be related to 'background' productivity. The results reported here (Fig. 2) corroborate Griffiths et al.'s (1982) results of enhanced seabird use of the APF. Jahncke et al. (2005) reported that STSH aggregated to forage on euphausiids and fish at the inner front in the southeast Bering Sea where local productivity was enhanced by the front.

The southern limit to STSH foraging is the pack ice edge, and STSH belong to the open-water assemblage of seabirds recorded from the Indian sector of the Southern Ocean (Woehler et al. 2003). Ainley et al. (1984) reported that the southern boundary of sooty shearwaters in the Ross Sea coincided with the appearance of icebergs. Weimerskirch \& Cherel (1998) reported at least 20 species of prey were taken by STSH, and more recent work by Connan et al. (2005) suggest a broad spectrum of myctophids and crustaceans comprise the primary dietary taxa for breeding STSH. STSH are capable of diving to $30 \mathrm{~m}$ or more (Weimerskirch \& Cherel 1998), and despite the presence of some of their prey species such as euphausiids and amphipods under the ice, appear to favour foraging in open water where they take myctophids. Cherel et al. (2005) describe foraging by adult STSH in Antarctic waters based on stable carbon and nitrogen isotope plasma levels. Our at-sea observations support the results of Cherel et al. (2005) and provide additional data on the spatial and temporal patterns in foraging by STSH from southeast Australia. Preliminary results from continuous plankton recorder surveys (http://aadc-maps.aad.gov.au/aadc/cpr/index.cfm) that describe the pelagic distribution of many of these prey taxa agree with the foraging localities proposed by Weimerskirch \& Cherel (1998) and Cherel et al. (2005).

We were unable to unequivocally relate foraging STSH to the shelf break, the MIZ or the AD, as these overlap spatially during the Antarctic summer months as the MIZ retreats southward past the $\mathrm{AD}$ and over the continental shelf. However, it is likely that physical processes that concentrate prey at or close to the surface may act synergistically in this area, providing a spatially and seasonally predictable food supply to foraging STSH. Similar synergies were proposed for the Ross Sea shelf by Ainley \& Jacobs (1981). This predictable and elevated prey supply may be what draws STSH southward of the APF later in the summer months. Chl a estimates from satellite-derived ocean colour images (SeaWiFS) provide corroborating evidence for higher productivity in the MIZ. During incubation, primary productivity $\pm 2^{\circ}$ of the APF was $0.25 \pm$ $0.04 \mathrm{mg} \mathrm{m}^{-3}$ for the period 1997-2003, compared to $0.74 \pm 0.17 \mathrm{mg} \mathrm{m}^{-3}$ for surface waters $4^{\circ}$ latitude northward from the coast: a 3 -fold increase in productivity. During the chick-rearing period, this increase was less, 
but still more than 2.5 -fold $\left(0.15 \pm 0.01 \mathrm{mg} \mathrm{m}^{-3}\right.$ at the APF compared to $0.39 \pm 0.13 \mathrm{mg} \mathrm{m}^{-3}$ for surface waters $4^{\circ}$ northward from the coast for the period 1998-2004). The southward shift in foraging STSH from the APF to the MIZ/AD/continental shelf is associated with the hatching of their eggs and the onset of the elevated energy demands of their chicks. As with other procellariiformes that have evolved a foraging strategy of highly efficient flight and the ability to return prey as stomach oil (Marchant \& Higgins 1990), STSH are foraging in Antarctic waters to feed their chicks in southeastern Australia, thousands of kilometres distant.

\section{Concordance of satellite tracking and direct observations}

The limited data available from satellite-tracked birds concur with the extensive at-sea observations examined here. Both previous satellite-tracking studies (of 1 and 3 individuals) clearly showed STSH flying rapidly and directly southwards from their colonies in southeast Australia to forage in Antarctic waters south of $60^{\circ} \mathrm{S}$ (Nicholls et al. 1998, Klomp \& Schultz 2000). The single bird of unknown breeding status tracked by Nicholls et al. (1998) flew to $63^{\circ} \mathrm{S}$ in $3 \mathrm{~d}$ during April 1996. The 3 breeding adults tracked by Klomp \& Schultz (2000) during the mid to late chick stage (February to April 1997) took 3 to $4 \mathrm{~d}$ to reach $60^{\circ} \mathrm{S}$. Once all 4 satellite-tracked birds reached Antarctic waters, they changed flight directions and headed west, paralleling the Antarctic coast and associated fast and pack ice edges. Nicholls et al. (1998) suggested that their bird flew over the AD. The 3 birds tracked by Klomp \& Schultz (2000) all foraged consistently south of $60^{\circ} \mathrm{S}$ and 1 bird foraged extensively between $90^{\circ} \mathrm{E}$ and $105^{\circ} \mathrm{E}$ before flying farther west to its last recorded location at $64^{\circ} \mathrm{S}, 37^{\circ} \mathrm{E}$.

\section{Flight speeds and ranges, foraging in Antarctic waters by STSH}

Daily foraging ranges of STSH at a colony in southeast Tasmania were calculated to be $300 \mathrm{~km}$ by Weimerskirch \& Cherel (1998), based on an estimated flight speed of $28 \mathrm{~km} \mathrm{~h}^{-1}$ and assumed that $50 \%$ of the time away from the colony was spent foraging and $50 \%$ in flight. Based on these assumptions, Weimerskirch \& Cherel (1998) suggested that STSH required a minimum of $5 \mathrm{~d}$ to fly south of the APF, forage within Antarctic waters and return to their colonies in southeast Tasmania. Baduini et al. (2001) estimated daily flight ranges of between $440 \mathrm{~km}$ and $1124 \mathrm{~km}$, depending on body lipid stores and incorporating a $50 \%$ flap- ping flight and $50 \%$ gliding flight. Increasing lipid reserves provided foraging birds with maximum flight ranges exceeding $8000 \mathrm{~km}$. Nicholls et al. (1998) reported that 1 satellite-tracked STSH flew $1124 \mathrm{~km}$ in $22.3 \mathrm{~h}$ while returning to Australia $\left(50.4 \mathrm{~km} \mathrm{~h}^{-1}\right)$ from a foraging trip in Antarctic waters, and Klomp \& Schultz (2000) reported a maximum range of $1012 \mathrm{~km}$ by a satellite-tracked male. Maximum flight speeds between $72.9 \mathrm{~km} \mathrm{~h}^{-1}$ during daytime (Nicholls et al. 1998) and $88 \mathrm{~km} \mathrm{~h}^{-1}$ over a $3 \mathrm{~h}$ period (Klomp \& Schultz 2000) were calculated from accurate satellite fixes of instrumented birds.

Based on dietary data, Weimerskirch \& Cherel (1998) showed that STSH breeding in Tasmania foraged south of the APF approximately $1000 \mathrm{~km}$ to the south of their colonies. This study, and the limited data available from satellite tracking of 4 birds, clearly shows that STSH forage well to the south of the APF, with the farthest south observations at $67^{\circ} \mathrm{S}$, within $250 \mathrm{~km}$ of the Antarctic coastline (see Fig. 1). In addition, foraging STSH also extend well to the west over Antarctic waters, reaching the western extent of Prydz Bay $\left(60^{\circ}\right.$ to $90^{\circ} \mathrm{E}$, see Woehler et al. 1991, 2003) during their breeding season. These birds could return to their colonies in $5.1 \mathrm{~d}$ (calculated on the basis of a mean return speed of $45.6 \mathrm{~km} \mathrm{~h}^{-1}$ [Nicholls et al. 1998] over a distance of $5600 \mathrm{~km}$ ).

Remarkably, the farthest west (i.e. most distant from colonies in southeast Australia) observations were made during the chick-rearing period (21 January to 15 April). The increasing energy demand of their growing chick requires more successful foraging by breeding adults. This may result in breeding adults foraging as far as $66^{\circ} \mathrm{S}$ at the very western extent of Prydz Bay (see Fig. 1), a region of enhanced productivity (Arrigo \& van Dijken 2003). At these localities, the birds are foraging over the Antarctic continental Shelf and north of, or in, the MIZ during the middle of the Antarctic summer. These extended foraging trips are reflected in the increasingly longer times between meals fed to the chick, decreasing from 1 meal every $1.2 \mathrm{~d}$ following hatch to just 1 meal in $25 \mathrm{~d}$ when the chick is 74 to $90 \mathrm{~d}$ old (late March to April: Marchant \& Higgins 1990).

\section{Ecosystem-scale roles of the MIZ, APF and AD}

This study has shown that foraging STSH, breeding in southeast Australia and Tasmania, make use of several physical oceanographic features in the southern Indian Ocean each summer. The birds use the various features at different times during the breeding season, but each feature contributes to the trophodynamics of the SOE by concentrating the 
shearwaters' prey taxa in spatially and/or temporally predictable localities that serve to facilitate energetically efficient foraging by the birds. The greatest demand for energy occurs when the STSH are feeding their growing chicks during the middle of the Antarctic summer. It is at this time that the MIZ forms annually around the Antarctic. At the upper trophic levels of the SOE, the location, extent and timing of the MIZ will affect and may even determine the feeding sites of Antarctic-breeding seabirds during the short summer breeding season. These elevated demands for food at sites close to breeding localities and at energetically-efficient densities ensures the importance of the MIZ, both to local breeding populations and to more distant populations such as STSH. Given the dynamic nature of the MIZ, investigations into the temporal and spatial use of the MIZ by seabirds as predators of marine resources may provide data on how the top predator community utilises an annual but spatially dynamic food resource during the short Antarctic summer. Previous investigations of the use of the MIZ by seabirds in the Southern Ocean have been undertaken in the Ross and Weddell Seas. In the Ross Sea, the greatest biomasses of seabirds were recorded in association with the MIZ (Ainley \& Jacobs 1981, Ainley 1985, Ainley et al. 1986), a similar situation to that reported for the Weddell Sea MIZ (Fraser \& Ainley 1986, van Franeker 1992). Preliminary investigations for the Prydz Bay region and East Antarctica (this study) indicate a similar situation.

Acknowledgements. We thank all observers who collected seabird-at-sea data since 1980/81. The project is supported by the Australian Antarctic Research Advisory Committee (Project 2208) and the data set is maintained at the Australian Antarctic Data Centre of the Australian Antarctic Division. This study is dedicated to the late Irynej Skira who was enthusiastic in all discussions of shearwaters in Tasmania and their travels southward. We thank the SeaWiFS Project (Code 970.2) and the Distributed Active Archive Center (Code 902) at the Goddard Space Flight Center, Greenbelt, MD 20771, for the production and distribution of the SeaWiFS data. Comments by D. Ainley and 4 anonymous referees improved the manuscript.

\section{LITERATURE CITED}

Abrams RW (1985) Environmental determinants of pelagic seabird distribution in the African sector of the Southern Ocean. J Biogeogr 12:473-492

Ainley DG, DeMaster DP (1990) The upper trophic levels in polar marine ecosystems. In: Smith WO Jr (ed) Polar Oceanography. Academic Press, San Diego, CA, p 599-630

Ainley DG, Jacobs SS (1981) Sea-bird affinities for ocean and ice boundaries in the Antarctic. Deep-Sea Res 28A: $1173-1185$

Ainley DG, O'Connor EF, Boekelheide RJ (1984) The marine ecology of birds in the Ross Sea, Antarctica. Am Ornithol Union Monogr 32

Ainley DG, Fraser WR, Ribic CA (1986) AMERIEZ 1986: oceanic factors affecting the occurrence of seabirds in the Scotia and Weddell Seas. Antarct J US 22:172-173

Ainley DG, Ribic CA, Fraser WR (1992) Does prey preference affect habitat choice in Antarctic seabirds? Mar Ecol Prog Ser 90:207-221

Ainley DG, Ribic CA, Spear LR (1993) Species-habitat relationships among Antarctic seabirds: a function of physical or biological factors? Condor 95:806-816

Ainley DG, Ribic CA, Fraser WR (1994) Ecological structure among migrant and resident seabirds of the ScotiaWeddell Confluence region. J Anim Ecol 63:347-364

Arrigo KR, van Dijken GL (2003) Phytoplankton dynamics within 37 Antarctic coastal polynya systems. J Geophys Res 108:3271, doi 10.1029/2002JC001739

Baduini CL, Lovvorn JR, Hunt GL Jr (2001) Determining the body condition of short-tailed shearwaters: implications for migratory flight ranges and starvation events. Mar Ecol Prog Ser 222:265-277

BirdLife International (2004) Tracking ocean wanderers: the global distribution of albatrosses and petrels. Global Procellariiform Tracking Workshop, 1-5 September 2003, Cambridge

Cherel Y, Hobson KA, Weimerskirch H (2005) Using stable isotopes to study resource acquisition and allocation in procellariiform seabirds. Oecologia 145:533-540

Comiso J (1999, updated 2003) Bootstrap sea ice concentrations for NIMBUS-7 SMMR and DMSP SSM/I. National Snow and Ice Data Center, Boulder, CO. Available at: http://nsidc.org/data/nsdic-0079.html

Connan M, Mayzaud $\mathrm{P}$, Boutoute $\mathrm{M}$, Weimerskirch $\mathrm{H}$, Cherel Y (2005) Lipid composition of stomach oil in a procellariiform seabird Puffinus tenuirostris: implications for food web studies. Mar Ecol Prog Ser 290:277-290

Fraser WR, Ainley DG (1986) Ice edges and seabird occurrences in Antarctica. BioScience 36:258-263

Griffiths AM, Siegfried WR, RW Abrams (1982) Ecological structure of a pelagic seabird community in the Southern Ocean. Polar Biol 1:39-46

Hunt GL (1991) Marine birds and ice-influenced environments of polar oceans. J Mar Syst 2:233-240

Hunt GL, Coyle KO, Hoffman S, Decker MB, Flint EN (1996) Foraging ecology of short-tailed shearwaters near the Pribilof Islands, Bering Sea. Mar Ecol Prog Ser 141:1-11

Jahncke J, Coyle KO, Hunt GL Jr (2005) Seabird distribution, abundance and diets in the central and eastern Aleutian Islands. Fish Oceanogr 14(suppl):160-177

Kerry KR, Horne RSC, Dorward DF (1983) Records of the short-tailed shearwater Puffinus tenuirostris in Antarctic waters. Emu 83:35-37

Klomp NI, Schultz MA (2000) Short-tailed shearwaters breeding in Australia forage in Antarctic waters. Mar Ecol Prog Ser 194:307-310

Knox GA (1994) The biology of the Southern Ocean. Cambridge University Press, Cambridge

Lovvorn JR, Baduini CL, Hunt GL Jr (2001) Modeling underwater visual and filter feeding by planktivorous shearwaters in unusual sea conditions. Ecology 82: $2343-2356$

Marchant S, Higgins PJ (1990) Handbook of Australian, New Zealand and Antarctic birds. Vol 1A, ratites to ducks. Oxford University Press, Melbourne

Mathot S, Dandois JM, Lancelot C (1992) Gross and net primary production in the Scotia-Weddell Sea sector of the Southern Ocean during spring 1988. Polar Biol 12:321-332 
Moore JK, Abbott MR, Richman JG (1999) Location and dynamics of the Antarctic Polar Front from satellite sea surface temperature data. J Geophys Res 104:3059-3073

Nicholls DG, Stampton P, Klomp NI, Schultz M (1998) Postbreeding flight to Antarctic waters by a short-tailed shearwater Puffinus tenuirostris. Emu 98:79-82

Orsi AH, Whitworth T III, Nowlin WD Jr (1995) On the meridional extent and fronts of the Antarctic Circumpolar Current. Deep-Sea Res I 42:641-673

Routh M (1949) Ornithological observations in the antarctic seas. Ibis 91:577-606

Skira IJ, Brothers NP, Pemberton D (1996) Distribution, abundance and conservation status of short-tailed shearwaters Puffinus tenuirostris in Tasmania, Australia. Mar Ornithol 24:1-14

Smith SL, Schnack-Schiel SB (1990) Polar zooplankton. In: Smith WO Jr (ed) Polar Oceanography. Academic Press, San Diego, CA, p 527-598

Smith WO, Sakshaug E (1990) Polar phytoplankton. In: Smith WO Jr (ed) Polar oceanography. Academic Press, San Diego, CA, p 477-526

Smith WO, Keene NK, Comiso JC (1988) Inter-annual variability in estimated primary productivity of the Antarcticmarginal ice zone. In: Sahrhage D (ed) Antarctic Ocean and resources variability. Springer Verlag, Berlin, p 131-139

van Franeker JA (1992) Top predators as indicators for ecosystem events in the confluence zone and marginal ice zone of the Weddell and Scotia Seas, Antarctica, Novem-

Editorial responsibility: Otto Kinne (Editor-in-Chief), Oldendorf/Luhe, Germany ber 1988 to January 1989 (EPOS Leg 2). Polar Biol 12: 93-102

Veit RR, Hunt GL Jr (1991) Broadscale density and aggregation of pelagic seabirds from a circumnavigational survey of the Antarctic Ocean. Auk 108:790-800

Veth C, Lancelot C, Ober S (1992) On processes determining the vertical stability of surface waters in the marginal ice zone of the north-western Weddell Sea and their relationship with phytoplankton bloom development. Polar Biol 12:237-243

Weimerskirch H, Cherel Y (1998) Feeding ecology of shorttailed shearwaters: breeding in Tasmania and foraging in the Antarctic? Mar Ecol Prog Ser 167:261-274

Wilson DL, Smith WO, Nelson DM (1986) Phytoplankton bloom dynamics of the western Ross Sea ice edge. I. Primary productivity and species-specific production. DeepSea Res 33:1375-1387

Woehler EJ (1995) Variability in foraging ecology and food consumption by seabirds at high latitudes. PhD thesis, University of California, Irvine

Woehler EJ (1997) Seabird abundance, biomass and prey consumption within Prydz Bay, Antarctica, 1980/81 to 1992/93. Polar Biol 17:371-383

Woehler EJ, Hodges CL, Watts DJ (1991) An atlas of the pelagic distribution and abundance of seabirds in the southern Indian Ocean. ANARE Res Notes 77

Woehler EJ, Raymond B, Watts DJ (2003) Decadal-scale seabird assemblages in Prydz Bay, East Antarctica. Mar Ecol Prog Ser 251:299-310

Submitted: July 8, 2005; Accepted: March 13, 2006

Proofs received from author(s): September 22, 2006 